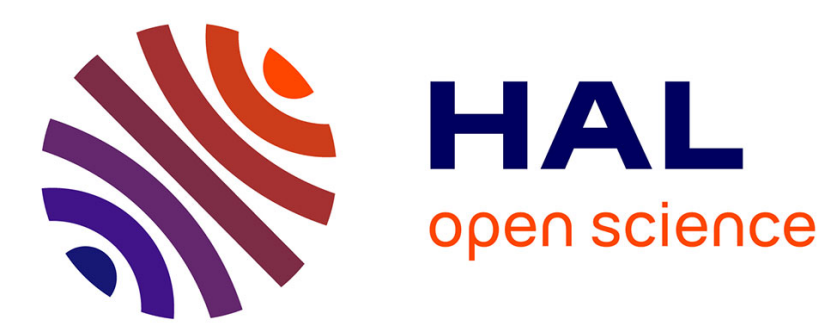

\title{
VARIATION OF THE OPTICAL ABSORPTION EDGE OF CsI AT HIGH PRESSURE
}

\author{
J. Itie, A. Polian, J. Besson
}

\section{To cite this version:}

J. Itie, A. Polian, J. Besson. VARIATION OF THE OPTICAL ABSORPTION EDGE OF CsI AT HIGH PRESSURE. Journal de Physique Colloques, 1984, 45 (C8), pp.C8-47-C8-51. 10.1051/jphyscol:1984809 . jpa-00224307

\section{HAL Id: jpa-00224307 https://hal.science/jpa-00224307}

Submitted on 1 Jan 1984

HAL is a multi-disciplinary open access archive for the deposit and dissemination of scientific research documents, whether they are published or not. The documents may come from teaching and research institutions in France or abroad, or from public or private research centers.
L'archive ouverte pluridisciplinaire HAL, est destinée au dépôt et à la diffusion de documents scientifiques de niveau recherche, publiés ou non, émanant des établissements d'enseignement et de recherche français ou étrangers, des laboratoires publics ou privés. 


\title{
VARIATION OF THE OPTICAL ABSORPTION EDGE OF CSI AT HIGH PRESSURE
}

\author{
J.P. Itie, A. Polian and J.M. Besson \\ Physique des Milieux Très Condensés, Université P. et M. Curie, \\ 113 E4, 4, Place Jussieu, 75230 Paris Cedex 05, France
}

\begin{abstract}
Résumé - L'absorption optique d'un monoeristal de Csl a été mesurácà température ambiante jusqu'a des pressions de 58 GPa, en utilisant le xénon comme milieux transmetteur de pression. La forme et la position du front d'absorption mesuré different de façon sigrificative des résultats obtenus sur des poudres, alors que seule la forme diffère des résultats précédents obtenus sur des monocristaux.
\end{abstract}

\begin{abstract}
Optical absurption was measured in single crystals of CsI at room temperature at pressures up to $38 \mathrm{GPa}$, using xenon as a pressure transmitting medium. The shape and position of the absorption edye are shour to differ significantly from results obtained on powders, whereas only the shape differs from results obtained on single crystals.
\end{abstract}

Investigations of the transition from isolating to conducting behavior of solids under pressure have been actively pursued lately. In cesium iodide, which is ionically isoelectronic with xenon, band closure should be attainable with a diamond anvil cell.

It has been studied amony other techniques by optical absorption measurements either on powder $(1-3)$ or un single crystals $(4-5)$. X-ray measurements shou one $(2-4$, crystallographic phase transitions around $40 \mathrm{GPa}$.

In this paper, we report optical absorption results on monocrystalline Csi up to 57,5 GPa using $X e$ as a pressure transmitting medium and compare it vith previous results.

Experiment isI and a ruby chip vere placed at the center of the hole of the stainless steel yasket. Sample and gasket hole stay centered with respect to the diamond culets during the experiment, within $10 \mathrm{~m}$. This minimizes the pressure gradient within the active volume of the sample. Pressure was measured by pressure shift of the luminescence line of ruby $(7)$. Unpolarized transmission spectra vas measurcd under a microscope, through a is frin region selected by a focal iris. Transmitted and reference beams vent through the CsI sample and xenon at all pressures.

No correction was made for reflexion losses at the Xe-CsI interface is: Fu sels of correction were made on the raw spectra.

- In the highly absorbiny, high energy range, diffused stray light induces a cunstant apparcint transirittancy which has been substracted.

- In the low-energy range, geometrical factors in the sclup and structural inhomogeneity in the sample induce a constant apparcnt absorbancy which must be fitted to $\alpha=0$. 
Pressure inhomoyeneity within the sample vas less than $2 \mathrm{GPa}$, by comparison with the line broadening of the ruby emission.

Results and analysis

Several features are apparent in rig. $l$.

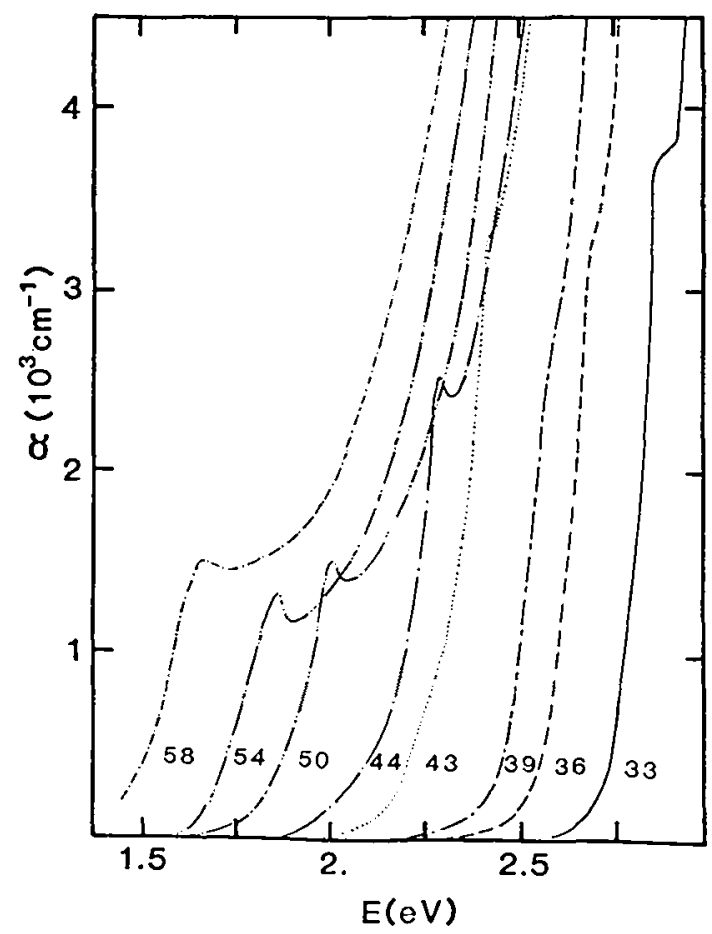

Fig. 1 : Absorption coefficient of a $\operatorname{Cs} I$ sample $(d:=1.0 \mu \mathrm{m}$ at $P=0$ in xenon at $\mathrm{T}=300 \mathrm{~K}$. Pressures are in GPa.

1) The absorption edge shifts continuously to lower energies with increasing pressure.

2) The shoulder on the absorption edge disappears when the pressure is increased up to $40 \mathrm{LPa}$.

3) When the pressure is further increased, it reappears a well-defined peak.

4) The apparent absorption spectrum is steeper at lover pressure.

The electronic band gap energy cannot be derived from the absorption edgc without some physical model for the transition. Here ve will examine the most likely process : alloved direct transition. In this case, it is natural to exarnine the assigment of the shoulder which appear belou $40 \mathrm{CPa}$ to an exciton. If we compare vith the room pressure spectrum $(8)$ we note that the inteyrated intensily decreases betveen 0 and $40 \mathrm{GPa}$ by a factor of 60 .

ror a fannier exciton, the integrated intensity can be written $(9)$ 


$$
\alpha \Gamma \propto \frac{\mu^{3}|M|^{2}}{\varepsilon^{7 / 2} E_{G}^{d}}
$$

$\alpha$ : absorption maximum, $\Gamma:$ full width at half maximum

$\mu$ : reduced mass of the exciton, $\varepsilon$ :the dielectric constant,

$M$ : the matrix element of the transition and Edgthe direct gap.

We take $M$ to be independent of pressure, and $\varepsilon$ to have the same pressure dependence as in $X e$, while $E_{G}^{d}$ decrease from 6 to $\sim 2$ ev $(10)$. Then a decrease of $\mu$ factor of 3 to 4 will account for the observed intensity and is consistent with the latest band structure calculations. This evaluation depends on several assumptions, and is only meant to show that the kink we observe, despite its small intensity, may be assigned with a direct exciton. Nevertheless, the shape of the high energy absorption is not that of direct continuum, with Coulomb interaction and must be related to the low-energy tail of a deeper level ( 9 ). In any case, the exciton energy (circles in $f i g$. 2) certainly represent a lower value for $E_{G \text {. }}^{d}$

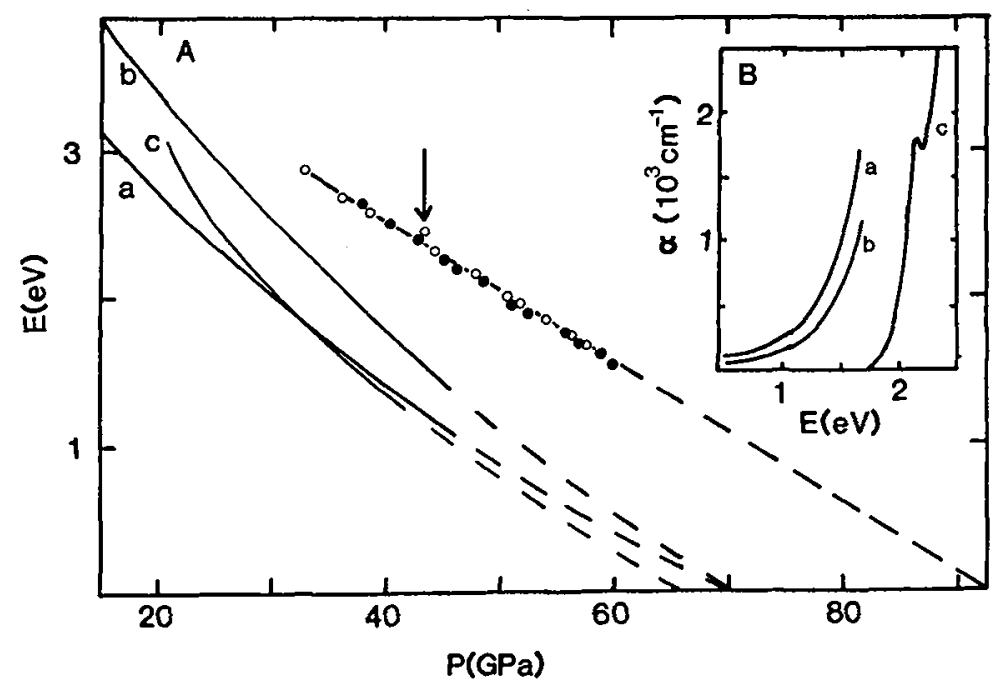

Fiq. 2 A : Energy gap (eV) vs pressure (CPa) in CsI.a and b are threshold energy gap $E_{t h}$ and direct energy gap of ref. $1 . c$ : absorption edge (ref. $2 ;$. Circles : exciton energy $E_{x}$ (this work). Points : "Exciton energy" (ref. 4). Dashed lines : extrapolations to zero energy. The arrow indicate the location anomaly of the exciton peak near the phase transition.

B. : Comparison of our results with those of $K$. Asaumi (réf. 6) a and $b$ : absorption coefficient of ref. 1, with samples thicknesses of 20 and $30 \mu \mathrm{m}$ at $46 \mathrm{GPa}$. $\mathrm{e}$ : absorption coefficient at $48 \mathrm{GPa}$ (this work).

Above $44 \mathrm{GPa}$, polarized light measurements should be done, in order to determine the optical gap. However, we have an indication of the position of the band edge. It. should be noted on figure 2 that apart from the transition pressure (arrow) $E_{x}$ versus. $P$ has a continuous variation, which fits with a very small volume variation at the transition, and presumably a small optical anisotropy.

Discussion and Conclusion

Comparison of our results (figure $2 A$ and $B$ ) with the preceding shows clearly two sets of results : on the one hand, results obtained on powders $(1-2)$, and on the other hand, those obtained on single crystals with a pressure transmitting medium (4-5) 
The shape and position of the edge are very different between the two set of results, whereas only the shape of the edge (see fig. 2.A) differenciates the "single crystal" results.

We interpret the differences between single crystal and powder by the higher pressure homogeneity over the active volume of single crystals, the use of a reference beam, and the nature itself of the crystal and the pouder. This discrepancy in the raw data leads to significant differences in the variation of the gap and of the extrapolated band closing pressure. Whereas pouder results predict a band closing between 65 and $70 \mathrm{GPa}(1-2)$, our linear extrapolation, which is a lower limit gives $93 \mathrm{GPa}$ and Makarenko et al.' (4) predict $110 \mathrm{GPa}$, using a non linear extrapolation.

These two last results fit reasonnably well with band structure calculations which predict $100 \pm 10 \mathrm{GPa}$. If the variation of the position of the energy gap fitsvery well (fig. 2A) the shape of the absorption curve is quite different. (fig. 3 ).

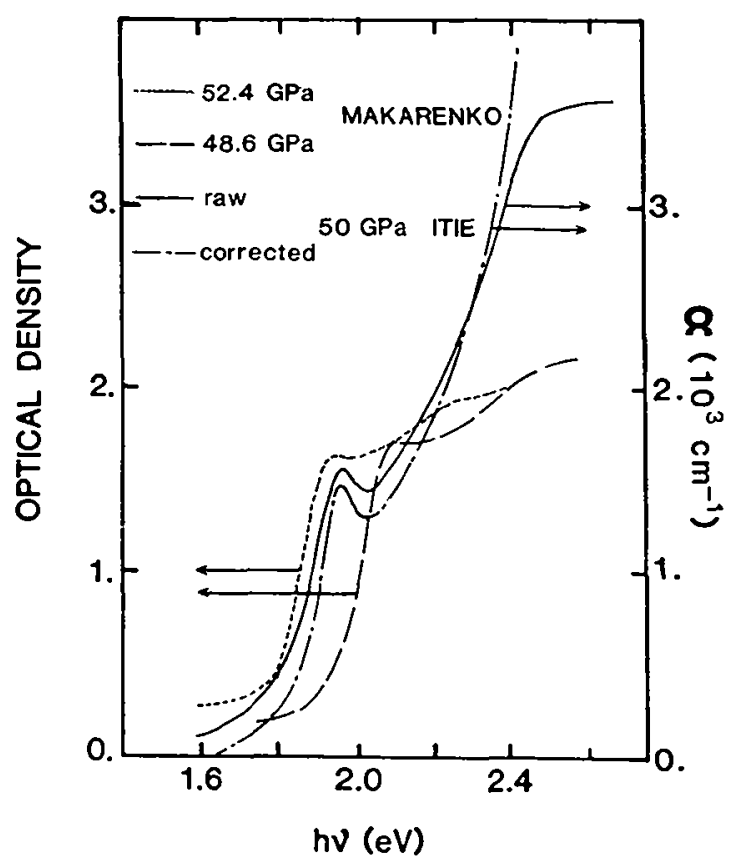

Fig. 3 Comparison of our results with those of Makarenko (ref. 4)--.-- and - : optical density (left hand scale) at 52.4 and $48.6 \mathrm{GPa}$, respectively from ref. 4 , coefficient (right hand scale) at $50 \mathrm{GPa}$ (this work).

In conclusion, it should be emphasized that the difference between the two set of results is very big. Then it seems to be necessary to use monocrystalline samples in transparent quasihydrostatic pressure transmitting medium, in order to extract meaningful data.

Note added in proof :

Absorption and $X$-ray measurements were performed recently on polycrystals (13). The band gap variation does not $f$ it with neither set of results discussed above. Indeed, in this work, samples are polycrystals and the stray low energy absorbancy is not corrected for. Moreover, the gap is arbitrarily located at a constant absorption coefficient $\left(9 \times 10^{3} \mathrm{~cm}^{-1}\right)$ for all pressures. 


\section{REFERENCES}

1) K. ASAUMI and Y. KONDO : Sol. St. Com. 40, 715 (1981)

2) T.L. HUANG and A.L. RUOFF : IX AIRAPT International High Pressure Conference, Albany (1983) (unpublished; ; Phys. Rev. B29, 112 (1984)

3) E. KNITTLE and R. JEANLOZ : Science 223, 53 (1984)

4) I.N. MAKARENKO, A.F. GONCHAROV and S.M. STISHOV : Phys. Rev. B29, 6018 (1984)

5) J.P. ITIE, A. POLIAN and J.M. BESSON : Phys. Rev. 830, 2309 (1984)

6) K. ASAUMI, Phys. Rev. B29, 1118 (1984)

7) H.K. MAO, P.M. BELL, J.W. SHANER and D.J. STEINBERG : J. Appl. Phys. 49, 3276 (1978)

8) K. TEEGARDEN and G. BALDINI : Phys. Rev. 155, 896 (1967)

9) R.J. ELLIOTT : Phys. Rev. 108, 1384 (1957)

R. LETOULLEC, N. PICCIDLI and J.C. CHERVIN : Phys. Rev. B22, 6162 (1980)

10) J.P. ITIE and R. LETOULLEC : This Conference.

11) 3. AIDUN, M.T.S. BUKOWINSKI and M. ROSS : Phys. Rev. B

12) J.T.VETELINO, 5.S. MITRA and K.V. NAMSOSHI : Phys. Rev. B2, 2167 (1970)

13) E. KNITTLE and R. JEANLOZ : private communication. 